\title{
Evaluation of overload effects on fatigue crack growth and closure
}

\author{
L.P. Borrego ${ }^{a, *}$, J.M. Ferreira ${ }^{b}$, J.M. Pinho da Cruz ${ }^{a}$, J.M. Costa ${ }^{b}$ \\ a Department of Mechanical Engineering, ISEC, Quinta da Nora, 3030 Coimbra, Portugal \\ ${ }^{\mathrm{b}}$ Department of Mechanical Engineering/FCT, University of Coimbra, Pólo II, 3030 Coimbra, Portugal
}

Received 15 March 2001; received in revised form 1 July 2002; accepted 15 July 2002

\begin{abstract}
Fatigue crack propagation tests with single tensile peak overloads have been performed in 6082-T6 aluminium alloy at several baseline $\Delta K$ levels and stress ratios of 0.05 and 0.25 . The tests were carried out at constant $\Delta K$ conditions. Crack closure was monitored in all tests by the compliance technique using a pin microgauge. The observed transient post-overload behaviour is discussed in terms of overload ratio, baseline $\Delta K$ level and stress ratio. The crack closure parameter $U$ was obtained and compared with the crack growth transients. Experimental support is given for the hypothesis that plasticity-induced closure is the main cause of overload retardation for plane stress conditions. Predictions based on crack closure measurements show good correlation with the observed crack growth rates for all the post-overload transients when discontinuous closure is properly taken into account.
\end{abstract}

(c) 2002 Elsevier Science Ltd. All rights reserved.

Keywords: Aluminium alloys; Overloads; Crack closure; Discontinuous closure; Partial closure model

\section{Introduction}

For many fatigue-critical parts of structures, vehicles and machines, fatigue crack propagation under service conditions generally involves random or variable amplitude, rather than constant amplitude loading conditions. Significant accelerations and/or retardations in crack growth rate can occur as a result of these load variations. Thus, an accurate prediction of fatigue life requires an adequate evaluation of these load interaction effects.

The 6000 aluminium series alloys are very frequently used in this type of applications, mainly due to the fact of allying a relatively high strength, good corrosion resistance and high toughness to a good formability and weldability. However, fatigue crack growth under variable load amplitudes in this series of aluminium alloys is not as well understood as for the 7000 and 2000 series. Furthermore, the amount of available data related to the material studied in this work is reduced.

\footnotetext{
${ }^{*}$ Corresponding author. Tel.: +351-239-790700; fax: +351-239-790701.

E-mail address: luis.borrego@dem.uc.pt (L.P. Borrego).
} 
The effects of single peak tensile overloads have been reported in many investigations [1-19] simply because this type of loading can lead to significant load interaction effects. Several mechanisms have been proposed to explain crack growth retardation, which include models based on residual stresses [19], crack closure [20], crack tip blunting [21], strain hardening [22], crack branching [23] and reversed yielding [24]. The precise micromechanisms that are responsible for these phenomena are not fully understood. In spite of some controversy, the effect of residual plastic deformation, which leads to compressive stresses before the crack tip and raises the crack opening load on subsequent crack growth (crack closure), has been identified as the most important aspect in explaining the variation of the characteristic features of post-overload transients [8-15].

However, some discrepancies appear when the experimental post-overload transients are compared with crack growth rates inferred from remote closure measurements and the $\mathrm{d} a / \mathrm{d} N$ versus $\Delta K_{\text {eff }}$ relation for the material [12-16]. Typically, the inferred and measured crack growth rates show good agreement only until the maximum retardation point or when crack growth rates are already recovering from the minimum value. Beyond this point predicted values tend to be lower than the experimental ones. Such behaviour has been attributed to the phenomenon of discontinuous closure [14,15,17] first identified experimentally by Fleck [13], i.e., the crack is open near the tip, but still shut near the overload location at loads below the crack opening load, inducing measurements of crack opening loads that are excessively high. Finite element analyses have shown that this phenomenon can occur depending on the loading variables [14,25]. Tsukuda et al. [18] have also corroborated the existence of discontinuous closure at high stress ratios due to single tensile overloads by finite element analysis. This investigation indicates that the stress at the crack tip becomes tensile before the crack fully opens at the overload location.

Recently, Donald and Paris [26], using a remote displacement gage, have observed that for the 6061-T6 and 2024-T3 aluminium alloys, closure measurements produced a good correlation between low stress ratio and high stress ratio (closure free) crack growth rate data obtained with $K$-increasing conditions. On the contrary, in the near-threshold regime with crack growth data obtained by the $K$-decreasing procedure, the measured opening loads were excessively high. To take this effect in consideration, Paris et al. [27] proposed a "partial closure model", suggesting that the effective range of $K$, between its real minimum and maximum is:

$$
\Delta K_{\mathrm{eff}}=K_{\mathrm{max}}-\frac{2}{\pi} K_{\mathrm{op}}-\sigma_{\mathrm{nom}} \sqrt{\frac{\pi d}{2}}
$$

where $K_{\mathrm{op}}$ is the stress intensity factor at opening load, $\sigma_{\text {nom }}$ is the nominal uniform stress that would be present at minimum load if the crack were absent, and $d$ is the distance between the crack tip and the contact zone behind the crack. It was further suggested [27] that the effective range of $K$ could be bounded by:

$$
K_{\mathrm{max}}-\frac{2}{\pi} K_{\mathrm{op}}-\left(1-\frac{2}{\pi}\right) K_{\mathrm{min}} \leqslant \Delta K_{\mathrm{eff}} \leqslant K_{\mathrm{max}}-\frac{2}{\pi} K_{\mathrm{op}}
$$

therefore, an approximate result could be given by the following simple expression:

$$
\Delta K_{\mathrm{eff}}=K_{\mathrm{max}}-\frac{2}{\pi} K_{\mathrm{op}}
$$

In spite of an apparent slight overestimation of $\Delta K_{\text {eff }}$ by Eq. (3), experimental results showed that, for several aluminium alloys, this equation produces very good correlation of fatigue crack growth data under load-reduction (threshold) simulations [26,27]. Incidentally, Newman [28] has also indicated that under conditions of remote (partial) closure the appropriate opening stress to calculate the effective stress is $0.62 \sigma_{\mathrm{op}}$, which is very close to $2 / \pi \sigma_{\mathrm{op}}$. 
It is important to notice that the partial closure model was physically established assuming that, under $\Delta K$ reduction simulations, the crack is open at tip and closed near the load reduction location, at loads below the crack opening load [27]. This is similar to the hypothesis of the discontinuous closure phenomenon for overload conditions [13]. Thus, it seems adequate to use this model to predict post-overload transients from far field closure measurements.

In recent work the authors [29] concluded that crack closure was able to explain the influence of the stress ratio on the fatigue crack growth rate for the 6082-T6 aluminium alloy in both regimes I and II of crack propagation. Furthermore, for overloads applied in constant load tests, the influence of several load parameters could be generally correlated with the variation of crack closure. The present work intends to analyse more extensively the post-overload crack growth and closure transients following single tensile overloads with different overload ratios, OLR, at several $\Delta K$ baseline levels, $\Delta K_{\mathrm{BL}}$, and stress ratios, $R$. The use of the partial closure model [27] to predict the post-overload transients will also be evaluated. For this purpose, fatigue crack growth tests under constant $\Delta K$ conditions were performed, resulting in controlled constant-crack-wake history, which is more sensitive to changes in fatigue crack growth rates associated with changing driving force mechanisms than constant- $\Delta P$ tests.

\section{Experimental details}

The material used in this research was an AlMgSi1 (6082) aluminium alloy with T6 heat treatment. The chemical composition and the mechanical properties are presented in Tables 1 and 2, respectively.

Fatigue tests were conducted, in agreement with ASTM E647 standard [30], using middle-tension (M(T)) specimens with $3 \mathrm{~mm}$ thickness. The specimens were obtained in the longitudinal transverse direction from a laminated plate. Fig. 1 illustrates the major dimensions of the samples used in the tests. The notch preparation was made by electrical-discharge machining. After that, the specimen surfaces were mechanically polished.

All experiments were performed in a servo-hydraulic, closed-loop mechanical test machine with $100 \mathrm{kN}$ load capacity, interfaced to a computer for machine control and data acquisition. All tests were conducted in air, at room temperature and with a load frequency of $20 \mathrm{~Hz}$. The specimens were clamped by hydraulic grips. The crack length was measured using a travelling microscope $(45 \times)$ with a resolution of $10 \mu \mathrm{m}$. Collection of data was initiated after achieving an initial crack length $2 a_{0}$ of approximately $12 \mathrm{~mm}$.

Table 1

Chemical composition of 6082-T6 aluminium alloy (wt.\%)

\begin{tabular}{lllllllll}
\hline $\mathrm{Si}$ & $\mathrm{Fe}$ & $\mathrm{Cu}$ & $\mathrm{Mn}$ & $\mathrm{Mg}$ & $\mathrm{Cr}$ & $\mathrm{Zn}$ & $\mathrm{Ti}$ & $\mathrm{Other}$ \\
\hline $0.7-1.3$ & 0.5 & 0.1 & $0.4-1$ & $0.6-1.2$ & 0.25 & 0.2 & 0.1 & 0.05 \\
\hline
\end{tabular}

Table 2

Mechanical properties of 6082-T6 aluminium alloy

\begin{tabular}{ll} 
Tensile strength, $\sigma_{\mathrm{UTS}}(\mathrm{MPa})$ & $300 \pm 2.5$ \\
Yield strength, $\sigma_{\mathrm{YS}}(\mathrm{MPa})$ & $245 \pm 2.7$ \\
Elongation, $\varepsilon_{\mathrm{r}}(\%)$ & 9 \\
Cyclic hardening exponent, $n^{\prime}$ & 0.064 \\
Cyclic hardening coefficient, $K^{\prime}(\mathrm{MPa})$ & 443 \\
Fatigue strength exponent, $b$ & -0.0695 \\
Fatigue strength coefficient, $\sigma_{\mathrm{f}}^{\prime}(\mathrm{MPa})$ & 485 \\
Fatigue ductility exponent, $c$ & -0.827 \\
Fatigue ductility coefficient, $\varepsilon_{\mathrm{f}}^{\prime}$ & 0.773 \\
\hline
\end{tabular}




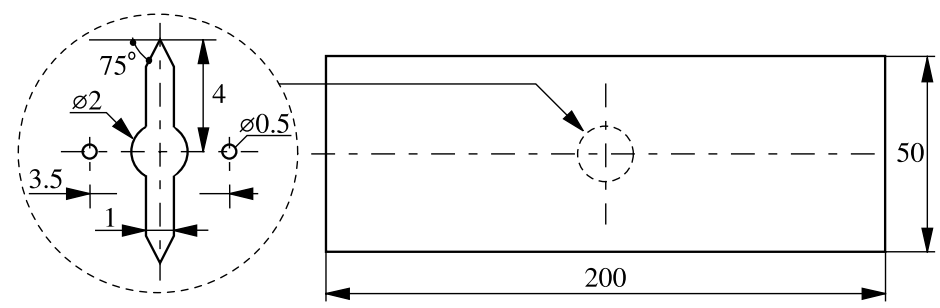

Fig. 1. Geometry of the $\mathrm{M}(T)$ specimen used in this work (dimensions in $\mathrm{mm}$ ).

The tests were performed under constant $\Delta K$ and stress ratio $R$ conditions, by manually shedding the load with crack growth. The load shedding intervals were chosen so that the maximum $\Delta K_{\mathrm{BL}}$ variation was smaller than $2 \%$. The overloads were applied under load control during one cycle by programming the increase in load to the designated overload value. After overloading, the baseline loading was resumed and the transient crack growth behaviour associated with the overload was carefully observed. The influence of a single tensile overload was investigated at $R=0.05$ and 0.25 . The crack growth rates were determined by the secant method [30].

Single tensile overload tests were performed at several $\Delta K$ baseline levels, ranging from 4 to $10 \mathrm{MPa} \mathrm{m}{ }^{1 / 2}$. The OLR was 1.5 and 2, which was defined as:

$$
\mathrm{OLR}=\frac{\Delta K_{\mathrm{OL}}}{\Delta K_{\mathrm{BL}}}=\frac{K_{\mathrm{OL}}-K_{\min }}{K_{\max }-K_{\min }}
$$

where $K_{\max }, K_{\min }$, and $K_{\mathrm{OL}}$ are the maximum, minimum and peak overload intensity factors, respectively.

Load-displacement behaviour was monitored at all crack measurements for each of the tests using a pin microgauge. The gauge pins were placed in two drilled holes of $0.5 \mathrm{~mm}$ diameter located above and below the centre of the notch (see Fig. 1). The distance between these points was $3.5 \mathrm{~mm}$. In order to collect as many load-displacement data as possible during a particular cycle, the frequency was reduced to $0.5 \mathrm{~Hz}$. Noise on the strain gauge output was reduced by passing the signal through a $1 \mathrm{~Hz}$ low-pass mathematical filter.

From the load-displacement records, variations of the opening load, $P_{\mathrm{op}}$, were derived using the technique known as maximization of the correlation coefficient [31]. This technique involves taking the upper $10 \%$ of the $P-\varepsilon$ data and calculating the least squares correlation coefficient. The next data pair is then added and the correlation coefficient is again computed. This procedure is repeated for the whole data set. The point at which the correlation coefficient reaches a maximum can then be defined as $P_{\mathrm{op}}$.

The fraction of the load cycle for which the crack remains fully open, parameter $U$, was calculated by the following equation:

$$
U=\frac{P_{\max }-P_{\mathrm{op}}}{P_{\max }-P_{\min }}
$$

The values of the effective stress intensity factor range, $\Delta K_{\text {eff }}$, are given by the expression:

$$
\Delta K_{\text {eff }}=K_{\max }-K_{\mathrm{op}}=U \Delta K
$$

During all the tests, the crack path at the specimen surface was carefully observed using an optical microscope. The fracture surfaces were observed in a Philips XL30 scanning electron microscope. The fracture surfaces profile and roughness at different distances from the specimen surfaces were also evaluated. The laser equipment Mahr RM600-3D was used for these measurements. The optical distance sensor works with an infrared laser whose beam is focused on the surface of the sample. The size of the spot is $1 \mu \mathrm{m}$ and the resolution of the equipment is $0.01 \mu \mathrm{m}$. The geometry of the surface of fatigued specimens was 
determined through analysis of profiles of the fracture surface, parallel to the main crack propagation direction.

\section{Results and discussion}

\subsection{Transient crack growth behaviour}

Fig. 2 illustrates the typical transient crack growth behaviour obtained when a specimen is subjected to a single tensile overload in a constant $\Delta K$ test. In Fig. 2(a) the crack length from the overload event, $a-a_{\mathrm{OL}}$, is plotted against the number of cycles from the point of overload application, $N-N_{\mathrm{OL}}$, where $a_{\mathrm{OL}}$ and $N_{\mathrm{OL}}$ are the crack length and the number of cycles at which the overload is applied, respectively. Differentiation of this data gives the corresponding crack growth response, which may be plotted in function of the crack length from the overload event, $a-a_{\mathrm{OL}}$, as illustrated in Fig. 2(b). There is a brief initial acceleration of crack growth rate immediately after the overload. The subsequent crack growth rate decreases until its minimum value is reached, followed by a gradual approach to the level of the baseline steady state. This trend is consistent with the behaviour normally reported in the literature [1-15]. The observed behaviour is usually referred to as delayed retardation of crack growth. Information from these two different plots may be used to determine both the extent and magnitude of retardation.

Generally the magnitude and extent of retardation is quantified by the parameters defined in Fig. 2 . The number of delay cycles, $N_{\mathrm{D}}$, is the difference between the number of cycles at which the steady state is achieved and the number of cycles that would occur for the same crack length at constant amplitude baseline loading, $N_{\mathrm{CA}}$. The overload affected crack growth increment, $\Delta a_{\mathrm{OL}}$, is the crack growth distance between the point of overload application and the point at which the crack growth rate recovers its initial value. The delay distance, $a_{\mathrm{D}}$, is the crack length that would exist at constant amplitude loading, if the number of cycles needed to achieve the steady state-growth were applied. $(\mathrm{d} a / \mathrm{d} N)_{\mathrm{CA}}$ is the constant
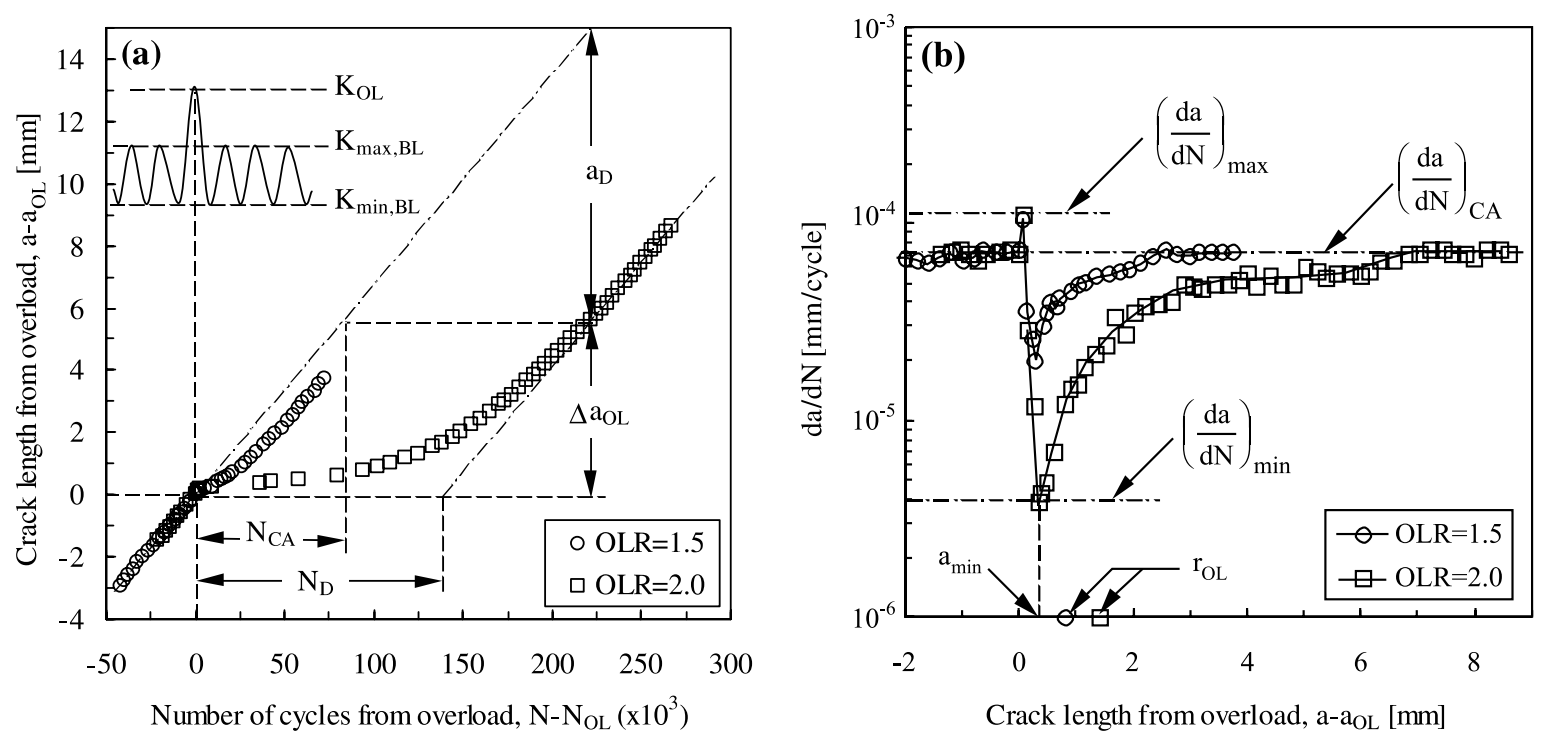

Fig. 2. Typical transient behaviour after a single tensile overload, OLR $=2.0$ and 1.5 at $\Delta K_{\mathrm{BL}}=8 \mathrm{MPa} \mathrm{m}^{1 / 2}$ and $R=0.05$ : (a) $\mathrm{crack}^{\mathrm{a}}$ length versus cycles, (b) crack growth rate versus crack length. 
Table 3

Features of the post-overload crack growth transients

\begin{tabular}{|c|c|c|c|c|c|c|c|c|c|}
\hline$R$ & OLR & $\begin{array}{l}\Delta K_{\mathrm{BL}} \\
\left(\mathrm{MPa} \mathrm{m}^{1 / 2}\right)\end{array}$ & $\begin{array}{l}\Delta a_{\mathrm{OL}} \\
(\mathrm{mm})\end{array}$ & $\begin{array}{l}a_{\mathrm{D}} \\
(\mathrm{mm})\end{array}$ & $\begin{array}{l}N_{\mathrm{D}} \\
(\mathrm{mm})\end{array}$ & $\begin{array}{l}a_{\min } \\
(\mathrm{mm})\end{array}$ & $\begin{array}{l}(\mathrm{d} a / \mathrm{d} N)_{\mathrm{CA}} \\
(\mathrm{mm} / \text { cycle })\end{array}$ & $\begin{array}{l}(\mathrm{d} a / \mathrm{d} N)_{\max } \\
(\mathrm{mm} / \text { cycle })\end{array}$ & $\begin{array}{l}(\mathrm{d} a / \mathrm{d} N)_{\min } \\
(\mathrm{mm} / \text { cycle })\end{array}$ \\
\hline \multirow[t]{8}{*}{0.05} & 1.5 & 4 & 0.26 & 0.03 & 4557 & 0.11 & $6.35 \times 10^{-6}$ & $6.35 \times 10^{-6}$ & $4.82 \times 10^{-6}$ \\
\hline & & 6 & 0.92 & 0.34 & 12865 & 0.18 & $2.67 \times 10^{-5}$ & $3.91 \times 10^{-5}$ & $8.54 \times 10^{-6}$ \\
\hline & & 8 & 2.57 & 1.36 & 18903 & 0.275 & $7.20 \times 10^{-5}$ & $1.21 \times 10^{-4}$ & $2.00 \times 10^{-5}$ \\
\hline & & 10 & 5.62 & 2.04 & 13270 & 0.365 & $1.54 \times 10^{-4}$ & $2.63 \times 10^{-4}$ & $3.53 \times 10^{-5}$ \\
\hline & 2 & 4 & 0.43 & 0.41 & 64285 & 0.135 & $6.35 \times 10^{-6}$ & $9.68 \times 10^{-6}$ & $1.01 \times 10^{-6}$ \\
\hline & & 6 & 2.72 & 2.33 & 87379 & 0.2 & $2.67 \times 10^{-5}$ & $4.11 \times 10^{-5}$ & $2.37 \times 10^{-6}$ \\
\hline & & 8 & 7.03 & 10.4 & 145709 & 0.345 & $7.20 \times 10^{-5}$ & $1.36 \times 10^{-4}$ & $3.89 \times 10^{-6}$ \\
\hline & & 9 & 12.6 & 24.8 & 237963 & 0.48 & $1.04 \times 10^{-4}$ & $1.84 \times 10^{-4}$ & $3.18 \times 10^{-6}$ \\
\hline \multirow[t]{8}{*}{0.25} & 1.5 & 4 & 0.20 & 0.09 & 3024 & 0.075 & $1.12 \times 10^{-5}$ & $1.12 \times 10^{-5}$ & $6.24 \times 10^{-6}$ \\
\hline & & 6 & 0.71 & 0.18 & 3914 & 0.13 & $4.61 \times 10^{-5}$ & $5.92 \times 10^{-5}$ & $1.33 \times 10^{-5}$ \\
\hline & & 8 & 1.79 & 1.17 & 10188 & 0.205 & $1.15 \times 10^{-4}$ & $1.58 \times 10^{-4}$ & $3.76 \times 10^{-5}$ \\
\hline & & 10 & 2.79 & 1.14 & 5451 & 0.27 & $2.10 \times 10^{-4}$ & $4.33 \times 10^{-4}$ & $5.71 \times 10^{-5}$ \\
\hline & 2 & 4 & 0.31 & 0.52 & 44516 & 0.1 & $1.12 \times 10^{-5}$ & $1.33 \times 10^{-5}$ & $1.61 \times 10^{-6}$ \\
\hline & & 6 & 1.58 & 1.97 & 42730 & 0.16 & $4.61 \times 10^{-5}$ & $5.70 \times 10^{-5}$ & $2.85 \times 10^{-6}$ \\
\hline & & 8 & 4.21 & 9.74 & 88504 & 0.28 & $1.15 \times 10^{-4}$ & $1.54 \times 10^{-4}$ & $8.51 \times 10^{-6}$ \\
\hline & & 9 & 6.81 & 9.45 & 67524 & 0.435 & $1.40 \times 10^{-4}$ & $3.23 \times 10^{-4}$ & $1.28 \times 10^{-5}$ \\
\hline
\end{tabular}

amplitude crack growth rate corresponding to the baseline level. The maximum and minimum crack growth rates reached following the overload are $(\mathrm{d} a / \mathrm{d} N)_{\max }$ and $(\mathrm{d} a / \mathrm{d} N)_{\min }$, respectively. The corresponding crack increments from the overload event are $a_{\max }$ and $a_{\min }$. Table 3 summarises the values of these parameters in function of $R$, OLR, and $\Delta K_{\mathrm{BL}}$.

The size of overload monotonic plastic zone, $r_{\mathrm{OL}}$, was also calculated, being presented in Figs. 2(b) and 3 for comparison. $r_{\mathrm{OL}}$ was evaluated, for a plane stress condition, from the following equation:

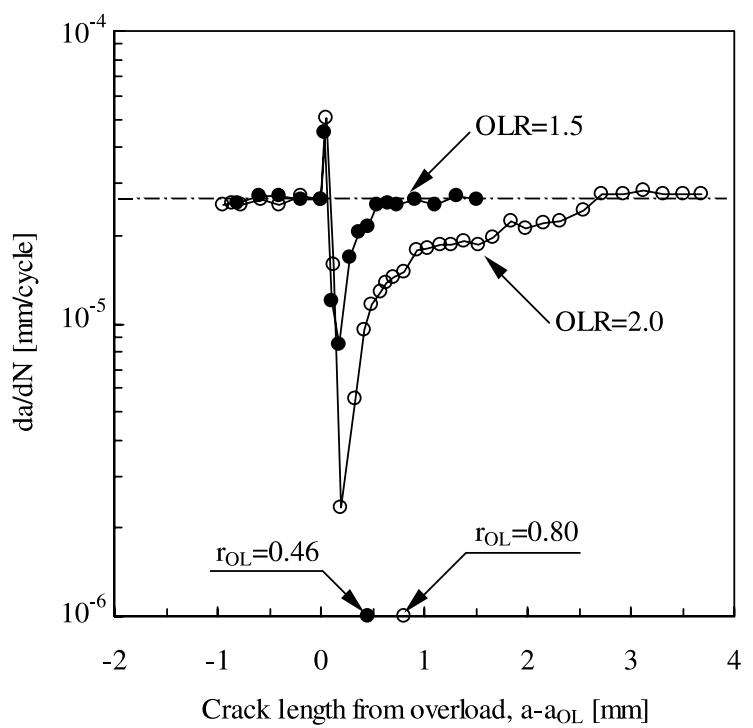

Fig. 3. Crack growth rate as a function of crack growth distance from the overload event for OLR values of 1.5 and 2 at $\Delta K_{\mathrm{BL}}=6$ $\mathrm{MPa} \mathrm{m}^{1 / 2}$ and $R=0.05$. 


$$
r_{\mathrm{OL}}=\frac{1}{\pi}\left(\frac{K_{\mathrm{OL}}}{\sigma_{\mathrm{Y}}}\right)^{2}
$$

where $K_{\mathrm{OL}}$ is the stress intensity factor at peak load during the overload cycle and $\sigma_{\mathrm{Y}}$ is the yield stress. This plastic zone superimposes the plastic zone created during regular crack growth at constant amplitude fatigue.

The influence of the OLR can be seen, at $\Delta K_{\mathrm{BL}}=8$ and $6 \mathrm{MPa} \mathrm{m}^{1 / 2}$, in Figs. 2 and 3, respectively. It is clear from these figures that the tests conducted for overloads with higher OLR yielded more crack growth retardation. For the overload applied at $\Delta K_{\mathrm{BL}}=8 \mathrm{MPa} \mathrm{m}^{1 / 2}$, the minimum value of the fatigue crack growth rate reached during the delayed retardation phase, $(\mathrm{d} a / \mathrm{d} N)_{\min }$, decreases from 0.28 to 0.05 of $(\mathrm{d} a / \mathrm{d} N)_{\mathrm{CA}}$, and the distance to the point at which this minimum occurs, $a_{\min }$, increases with OLR. The crack growth increment affected by the overload, $\Delta a_{\mathrm{OL}}$, and the delay cycles, $N_{\mathrm{D}}$, increase with OLR, representing a fatigue life increase of approximately eight times. For the overloads applied at $\Delta K_{\mathrm{BL}}=6$ $\mathrm{MPa} \mathrm{m}^{1 / 2}, a_{\mathrm{min}}, \Delta a_{\mathrm{OL}}$ and $N_{\mathrm{D}}$ also increase with OLR, representing an increase in fatigue life of about seven times. For these loading conditions $(\mathrm{d} a / \mathrm{d} N)_{\min }$ decreases from 0.32 to 0.09 relatively to $(\mathrm{d} a / \mathrm{d} N)_{\mathrm{CA}}$. As shown in Table 3, the described trends were observed for all the $\Delta K_{\mathrm{BL}}$ analysed in this work at both $R$ ratios of 0.05 and 0.25 . Therefore, the magnitude and extent of crack retardation increase with the level of the OLR, accordingly to many other studies $[1,2,12,15,18]$.

It is worthwhile to notice that the maximum fatigue crack growth rate achieved during the initial period of acceleration, $(\mathrm{d} a / \mathrm{d} N)_{\max }$, increases only slightly with OLR: from 1.69 to 1.89 and 1.47 to 1.54 of $(\mathrm{d} a / \mathrm{d} N)_{\mathrm{CA}}$, for $\Delta K_{\mathrm{BL}}=8$ and $6 \mathrm{MPa} \mathrm{m}^{1 / 2}$, respectively. For all the conditions analysed the increase in crack growth rate takes place only in a distance ranging from 0.06 to $0.1 \mathrm{~mm}$ after application of the overload, which represents a very small part of the overload affected crack increment. For the tests conducted for $\mathrm{OLR}=1.5$ at $\Delta K_{\mathrm{BL}}=4 \mathrm{MPa} \mathrm{m}^{1 / 2}$ the period of initial acceleration was not detected. For these loading conditions, the length of the transient region over which crack growth rates are affected by the overload is larger than $r_{\mathrm{OL}}$ calculated from Eq. (7), as showed in Figs. 2(b) and 3.

Fig. 4 presents the influence of the $\Delta K$ baseline level, $\Delta K_{\mathrm{BL}}$, at which the overload is applied, in terms of the normalized crack growth ratio, $(\mathrm{d} a / \mathrm{d} N) /(\mathrm{d} a / \mathrm{d} N)_{\mathrm{CA}}$, against $a-a_{\mathrm{OL}}$. Fig. 4(a) and (b) present the
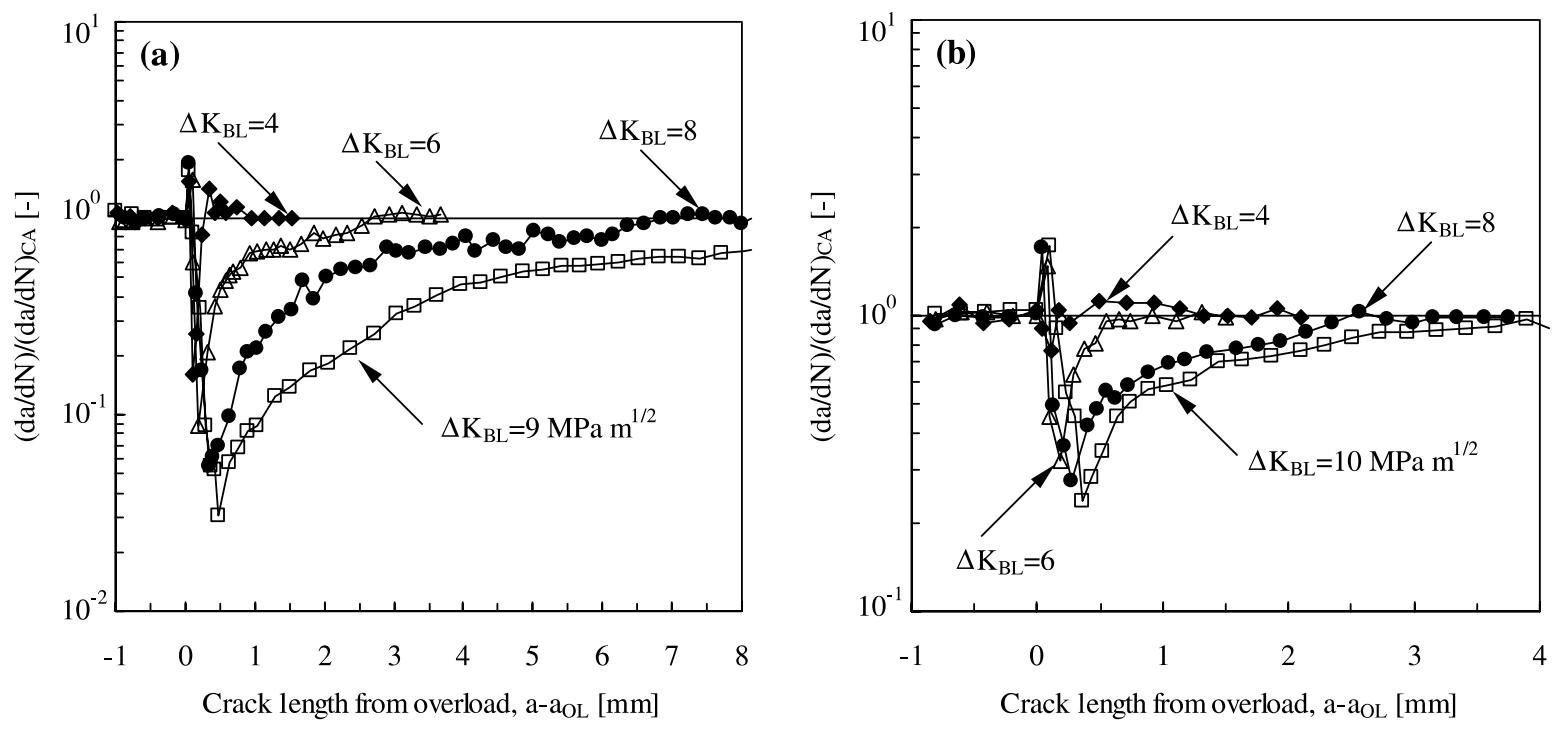

Fig. 4. Effect of $\Delta K$ baseline level on the normalized crack growth rate, $R=0.05$ : (a) OLR $=2.0$, (b) OLR $=1.5$. 
results obtained at $R=0.05$ for OLR $=2$ and 1.5, respectively. These figures show that crack growth retardation increases significantly with $\Delta K_{\mathrm{BL}}$. The values of parameters $\Delta a_{\mathrm{OL}}, a_{\min }$ and $N_{\mathrm{D}}$ increase (see Table 3 for details) as $\Delta K_{\mathrm{BL}}$ is increased from the lower to the higher $\Delta K_{\mathrm{BL}}$ analysed, corresponding to an increase in fatigue life of approximately four and three times for OLR $=2$ and 1.5 , respectively. The maximum and minimum values of the crack growth rate achieved during the corresponding transient period increase and decrease, respectively. For OLR $=2,(\mathrm{~d} a / \mathrm{d} N)_{\min }$ decreases from 0.16 to 0.03 of $(\mathrm{d} a / \mathrm{d} N)_{\mathrm{CA}}$ as $\Delta K_{\mathrm{BL}}$ is increased from 4 to $9 \mathrm{MPa} \mathrm{m}^{1 / 2}$, and for OLR $=1.5(\mathrm{~d} a / \mathrm{d} N)_{\min }$ decreases from 0.75 to 0.23 of $(\mathrm{d} a / \mathrm{d} N)_{\mathrm{CA}}$ as $\Delta K_{\mathrm{BL}}$ is increased from 4 to $10 \mathrm{MPa} \mathrm{m}^{1 / 2}$. The maximum fatigue crack growth rate achieved during the initial period of acceleration, $(\mathrm{d} a / \mathrm{d} N)_{\max }$, increases only slightly with $\Delta K_{\mathrm{BL}}$ and is approximately $1.5-2$ of $(\mathrm{d} a / \mathrm{d} N)_{\mathrm{CA}}$ for all the analysed $\Delta K_{\mathrm{BL}}$. These results are opposite to those reported by Ward-Close et al. [2] where the initial acceleration after an overload become more pronounced as $\Delta K_{\mathrm{BL}}$ decreases. The curves for $\Delta K_{\mathrm{BL}}=4$ present an acceleration phase before recovering. The acceleration following the retardation was also detected for steels at a low stress ratio [12] and in aluminium alloy 2017-T3 at high stress ratios [18].

The influence of the stress ratio on the transient crack growth behaviour following a single tensile overload can be seen in Fig. 5 for different OLR and $\Delta K_{\mathrm{BL}}$ levels. Fig. 5(a) and (b) present the results obtained for OLR $=2$ at $\Delta K_{\mathrm{BL}}=6 \mathrm{MPa} \mathrm{m}^{1 / 2}$ and for $\mathrm{OLR}=1.5$ at $\Delta K_{\mathrm{BL}}=10 \mathrm{MPa} \mathrm{m}^{1 / 2}$, respectively. From these limited data it is apparent that the overload effect is reduced, although only slightly, when the stress ratio is increased from 0.05 to 0.25 . The values of $N_{\mathrm{D}}$ and $\Delta a_{\mathrm{OL}}$ decrease when $R$ increases (see Table 3 for details) corresponding to a fatigue life reduction of approximately $50 \%$ and $60 \%$ for OLR $=2$ at $\Delta K_{\mathrm{BL}}=6 \mathrm{MPa} \mathrm{m}^{1 / 2}$ (Fig. 5(a)) and for OLR $=1.5$ at $\Delta K_{\mathrm{BL}}=10 \mathrm{MPa} \mathrm{m}^{1 / 2}$ (Fig. 5(b)), respectively. The relative maximum $\mathrm{d} a / \mathrm{d} N$ achieved during the initial period of acceleration also decreases. It is worthwhile to notice that, despite of the described trends, for OLR $=2$ at $\Delta K_{\mathrm{BL}}=6 \mathrm{MPa} \mathrm{m}^{1 / 2}$ the minimum $\mathrm{d} a / \mathrm{d} N$ value reached during the delayed retardation phase is slightly lower for $R=0.25$ than for $R=0.05$. However, the distance to the point for which this minimum happens decreases with the increase of $R$. For a stainless steel, Shin and Hsu [15] also observed that, after a certain stress ratio, a further increase in $R$ resulted in a slightly more deep $(\mathrm{d} a / \mathrm{d} N)_{\min }$.
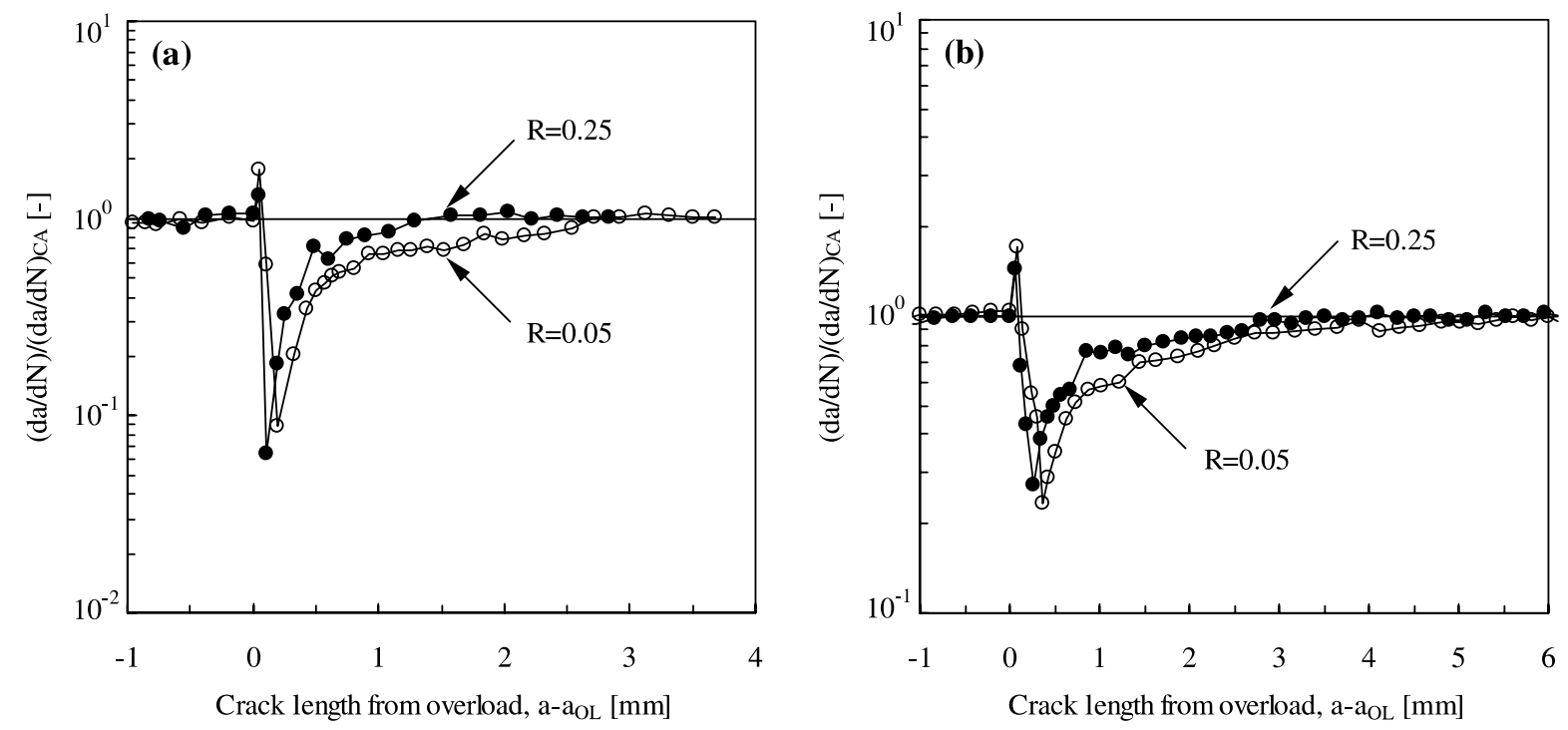

Fig. 5. Effect of stress ratio on the normalized crack growth rate: (a) OLR $=2.0$ at $\Delta K_{\mathrm{BL}}=6 \mathrm{MPa} \mathrm{m}^{1 / 2}$, (b) $\mathrm{OLR}=1.5$ at $\Delta K_{\mathrm{BL}}=10$ $\mathrm{MPa} \mathrm{m}^{1 / 2}$. 
Table 3 shows that, for all the analysed loading conditions, the magnitude and extent of crack growth retardation decrease with increasing $R$. The same behaviour has been reported in the literature for steels $[1,7,11,15]$ and for 2017-T3 aluminium alloy [18].

\subsection{Features of the post-overload crack growth transients}

To verify in more detail the described trends, the variation of the more relevant parameters indicated in Fig. 2 will now be presented for all the analysed loading conditions. Fig. 6 shows the variation of crack
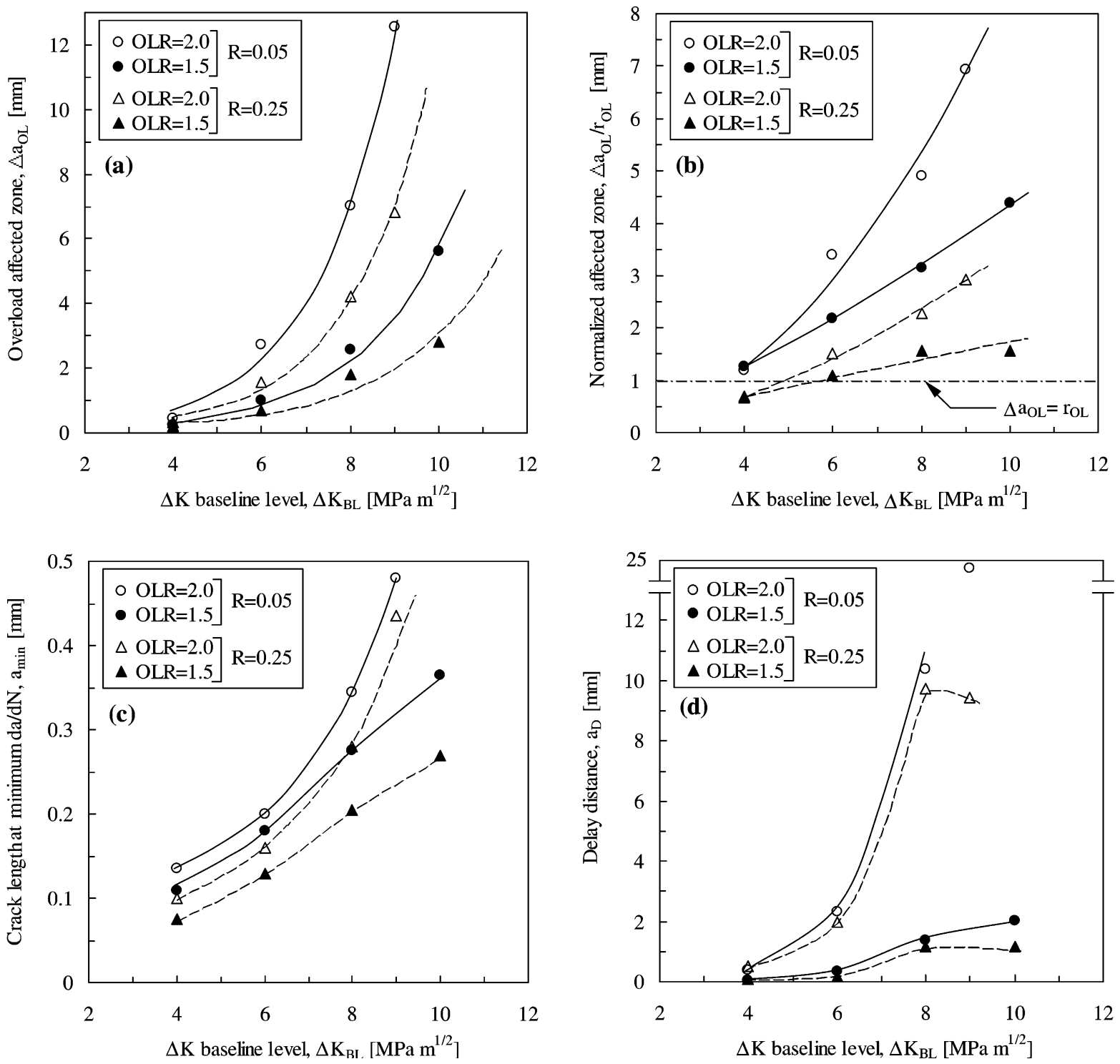

Fig. 6. Variation of crack length related parameters in function of $\Delta K$ baseline level: (a) overload affected zone, (b) comparison between $\Delta a_{\mathrm{OL}}$ and the overload plastic zone, (c) crack length corresponding to maximum retardation, (d) delay distance. 
length related parameters, $\Delta a_{\mathrm{OL}}, \Delta a_{\mathrm{OL}} / r_{\mathrm{OL}}, a_{\mathrm{min}}$ and $a_{\mathrm{D}}$ in function of $\Delta K$ baseline level for the two different analysed overload and stress ratios. From Fig. 6(a) it is evident that, for all conditions, the extent of the overload affected zone, $\Delta a_{\mathrm{OL}}$, increases with $\Delta K_{\mathrm{BL}}$, OLR and decreasing $R$. The influence of OLR and $R$ increases with $\Delta K_{\mathrm{BL}}$. Also, the effect of OLR on $\Delta a_{\mathrm{OL}}$ seems to be more important than the effect of $R$.

Fig. 6(b) presents the variation of the ratio $\Delta a_{\mathrm{OL}} / r_{\mathrm{OL}}$, where $r_{\mathrm{OL}}$ was calculated from Eq. (7), against $\Delta K_{\mathrm{BL}}, \mathrm{OLR}$, and $R$. For $R=0.05$ the value of $\Delta a_{\mathrm{OL}} / r_{\mathrm{OL}}$ is approximately unity only for $\Delta K_{\mathrm{BL}}=4 \mathrm{MPa} \mathrm{m}{ }^{1 / 2}$ and for $R=0.25$ the parameter $\Delta a_{\mathrm{OL}}$ is approximately equal to $r_{\mathrm{OL}}$ for $\Delta K_{\mathrm{BL}}=4 \mathrm{MPa} \mathrm{m}^{1 / 2}$ and for OLR $=1.5$ at $\Delta K_{\mathrm{BL}}=6 \mathrm{MPa} \mathrm{m}^{1 / 2}$. For the other analysed conditions the ratio $\Delta a_{\mathrm{OL}} / r_{\mathrm{OL}}$ is higher than unity and increases with OLR, $\Delta K_{\mathrm{BL}}$ and decreasing stress ratio. Therefore, it is clear that for the same material and specimen thickness, depending on the loading variables, the overload affected crack increment can be of the same order as well as much larger than $r_{\mathrm{OL}}$. Both trends of $\Delta a_{\mathrm{OL}}$ equal to $[3,18]$ or much larger than $[2,4,11-13,15]$ the overload monotonic plastic zone calculated for plane stress conditions, have been reported. It is worthwhile to notice that, in contrast with the variation of $\Delta a_{\mathrm{OL}}$, the ratio $\Delta a_{\mathrm{OL}} / r_{\mathrm{OL}}$ seems to be more effectively influenced by $R$ than by OLR.

The influence of $\Delta K_{\mathrm{BL}}$, OLR and $R$ on the distance to the point at which $(\mathrm{d} a / \mathrm{d} N)_{\min }$ is reached, $a_{\min }$, is presented in Fig. 6(c). As expected, $a_{\min }$ increases with $\Delta K_{\mathrm{BL}}$ and OLR and decreases as $R$ increases. From this figure it is apparent that the influence of $R$ on $a_{\min }$ is approximately constant for both low and high $\Delta K_{\mathrm{BL}}$, and that the OLR effect increases for high $\Delta K$ baseline levels. The crack length $a_{\min }$ represents 25 $40 \%$ and $15-25 \%$ of the overload plastic zone for $R=0.05$ and 0.25 , respectively. However, represents less than $10 \%$ of $\Delta a_{\mathrm{OL}}$ for the higher $\Delta K_{\mathrm{BL}}$.

The values of the delayed distance for the different loading conditions used during the experimental tests can be seen in Fig. 6(d). It is evident that in general $a_{\mathrm{D}}$ increases significantly with OLR and $\Delta K_{\mathrm{BL}}$, and decreases only slightly with increasing $R$. The effect of OLR is more pronounced than the effect of $R$. For $R=0.25$ and $\Delta K_{\mathrm{BL}}$ levels higher than $8 \mathrm{MPa} \mathrm{m}^{1 / 2}$ there is a small decrease of $a_{\mathrm{D}}$.

Finally, the influence of the different loading variables on the delay cycles, $N_{\mathrm{D}}$, and on the normalized delay cycles, $N_{\mathrm{D}} / N_{\mathrm{CA}}$, is presented in Fig. 7(a) and (b), respectively. As expected, a strong influence of $\Delta K_{\mathrm{BL}}$,
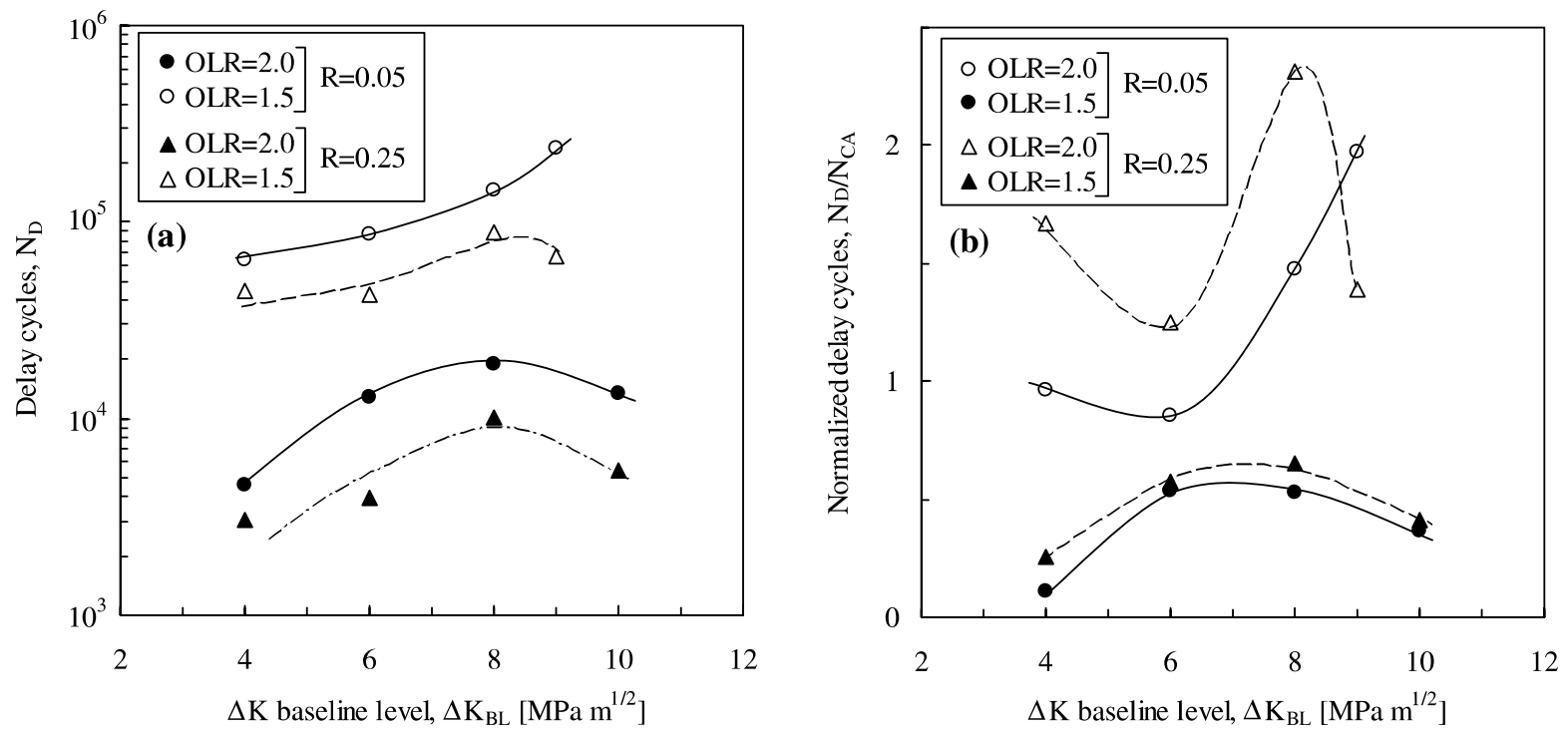

Fig. 7. Influence of the different loading variables on: (a) delay cycles, (b) normalized delay cycles. 
OLR and $R$ was observed. The delay cycles increase with OLR, $\Delta K_{\mathrm{BL}}$ and decreasing $R$, however as for $a_{\mathrm{D}}$, a further increase in $\Delta K_{\mathrm{BL}}$ above $8 \mathrm{MPa} \mathrm{m}^{1 / 2}$ generally yields a lower number of delay cycles.

Fig. 7(b) shows that $N_{\mathrm{D}} / N_{\mathrm{CA}}$ increases with the stress ratio. This means that, although the absolute value of $N_{\mathrm{D}}$ is enhanced at the lower stress ratio, at the higher $R$ it represents a larger percentage of the corresponding baseline cycles. For $N_{\mathrm{D}} / N_{\mathrm{CA}}$ the influence of OLR is minimum at an intermediate $\Delta K_{\mathrm{BL}}$ value of 6 $\mathrm{MPa} \mathrm{m}^{1 / 2}$ and increases at the highest and lowest $\Delta K_{\mathrm{BL}}$ analysed. For OLR $=1.5$ the value of $N_{\mathrm{D}}$ is always lower than the corresponding number of cycles in the baseline level $N_{\mathrm{CA}}\left(N_{\mathrm{D}} / N_{\mathrm{CA}}<0.6\right)$, while for OLR $=2 N_{\mathrm{D}}$ is approximately equal or superior to $N_{\mathrm{CA}}\left(N_{\mathrm{D}} / N_{\mathrm{CA}} \geqslant 1\right)$. The $N_{\mathrm{D}} / N_{\mathrm{CA}}$ versus $\Delta K_{\mathrm{BL}}$ plots are $\mathrm{U}$ shaped curves, indicating minor and greater retardation effect for an intermediate $\Delta K_{\mathrm{BL}}$ value for OLR $=2$ and 1.5 , respectively.

These two unequal trends of $U$ shaped curves have been observed for different materials and for the same OLR of $2.0[1-4,11,15]$. In this work the different behaviour is present for the same material. Therefore, the OLR seems to be a major factor in determining the type of $\Delta K_{\mathrm{BL}}$ influence on the retardation effect.

\subsection{Crack closure}

Fig. 8 illustrates the typical crack closure response obtained following tensile peak overloads in 6082-T6 aluminium alloy. The obtained data are plotted in terms of the normalized load ratio parameter $U$, calculated by Eq. (5), against the crack growth increment from the point of overload application. Fig. 8(a)-(c) show crack closure data corresponding to crack growth rates presented in Figs. 3, 4(a) and 5(a), respectively, showing, in this way, the crack closure variation at several OLR, $\Delta K_{\mathrm{BL}}$ and $R$.

It is clear that the crack closure data show basically the same trend as the corresponding experimentally observed crack growth rate response. Prior to the overload the $U$ parameter at the baseline loading level is relatively stable. Upon application of the overload, $U$ rapidly increases followed by a decrease to a minimum value, $U_{\min }$, and then increases gradually towards the corresponding value of the baseline level. It is important to notice that the decrease in $U$ is not immediate after the overload application, but on the contrary decreases slowly towards the minimum value. This is in accordance with delayed retardation behaviour observed on crack growth rate transients. In general $U_{\min }$ occurs for a crack increment after the overload, $a_{U_{\min }}$ identical to $a_{\min }$. However, the pre-overload value is not attained at least until a crack increment after overloading greater than the corresponding $\Delta a_{\mathrm{OL}}$ is reached. This fact is attributed to discontinuous closure and will be discussed later on.

Fig. 8(a) shows that the parameter $U$ prior to the overload is approximately constant and equal to 0.82 . The maximum value of $U$ attained, $U_{\max }$, increases from 0.9 to 0.95 and $U_{\min }$ decreases from 0.58 to a value of 0.45 as OLR is increased from 1.5 to 2 , corresponding to a decrease of approximately $30 \%$ and $45 \%$ of the baseline $U$ level, respectively. Similarly, the results presented in Fig. 8(b) indicate that the normalized load parameter $U$ also decreases with increasing $\Delta K_{\mathrm{BL}}$. The minimum $U$ attained during the test for OLR $=2$ at $\Delta K_{\mathrm{BL}}=4 \mathrm{MPa} \mathrm{m}^{1 / 2}$ was 0.55 while at $\Delta K_{\mathrm{BL}}=9 \mathrm{MPam}^{1 / 2}$ was 0.27 , implying an $U_{\min }$ reduction of approximately $50 \%$. As expected, the crack length $a_{U_{\min }}$ increases with $\Delta K$ baseline level. Moreover, these values correspond approximately to the crack length where the minimum value of the crack growth rate is reached. Fig. 8(c) shows that in spite of $U_{\min }$ presents approximately the same value for $R=0.05$ and 0.25 , generally parameter $U$ increases with $R$. Prior to the overload $U$ increases approximately $20 \%$ but after overloading this increase is slightly higher, typically $25 \%$. It is important to notice that for $R=0.25$, although crack closure is absent during baseline cycling prior to the overload, this mechanism could still be activated by the overload. Similar behaviour was also reported by Shin and Hsu [15] for a stainless steel.

The results presented in Fig. 8 show that in general the normalized load parameter $U$ decreases, i.e., crack closure increases, with increasing OLR and $\Delta K$ baseline level and, also, with decreasing stress ratio. When $U$ decreases the minimum effective driving force behind the crack is also decreased. The corresponding crack growth rates must therefore be lower. Thus, the observed effect of OLR, $\Delta K_{\mathrm{BL}}$ and $R$ on the crack retardation 

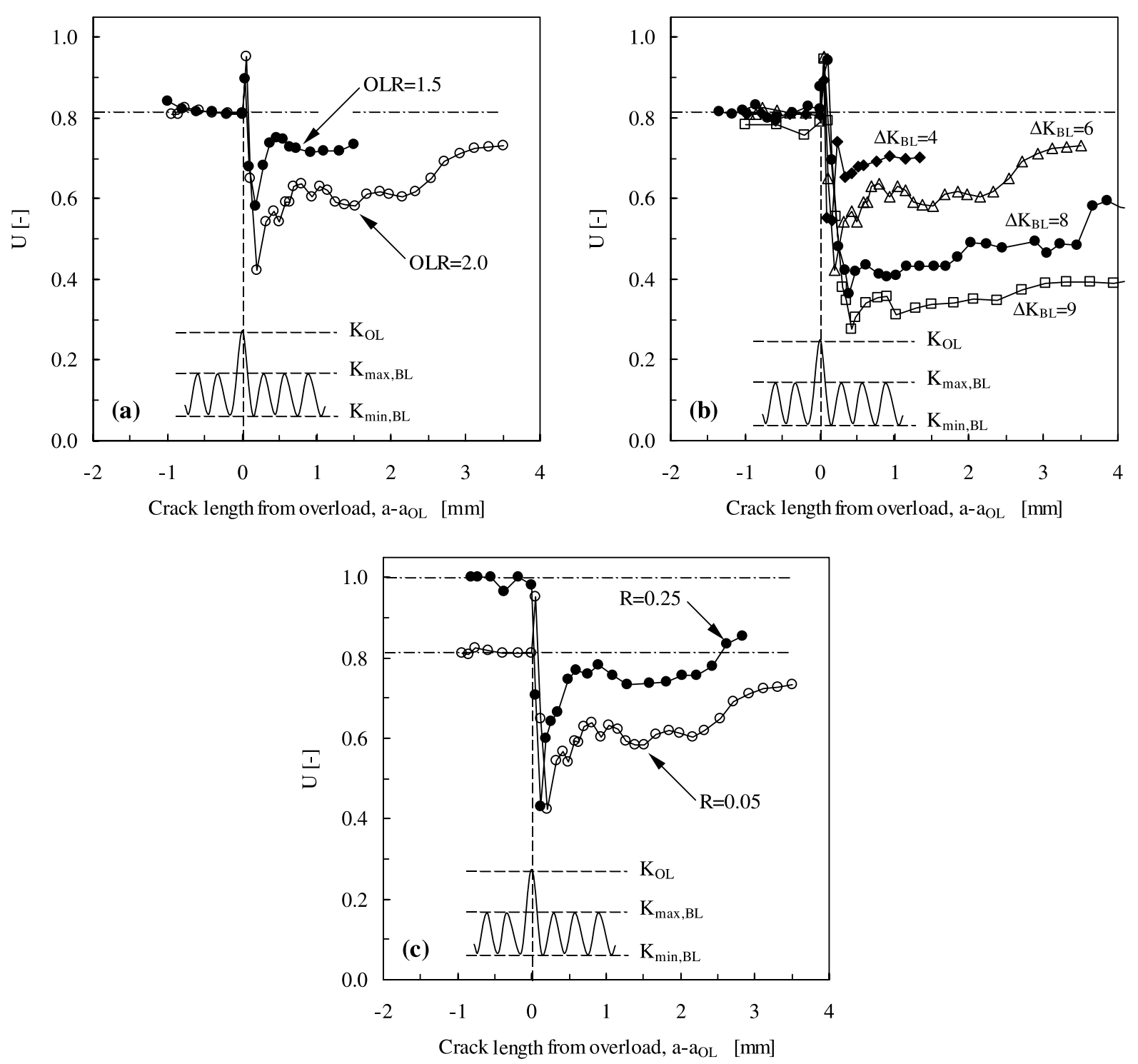

Fig. 8. Crack closure response following single peak overloads: (a) effect of OLR $\left(\Delta K_{\mathrm{BL}}=6 \mathrm{MPa} \mathrm{m}^{1 / 2}\right.$ and $\left.R=0.05\right)$, (b) effect of $\Delta K$ baseline level (OLR $=2$ and $R=0.05)$, (c) effect of stress ratio $\left(\mathrm{OLR}=2\right.$ and $\left.\Delta K_{\mathrm{BL}}=6 \mathrm{MPam}^{1 / 2}\right)$.

behaviour is in accordance with the variation of crack closure. An increase in OLR or $\Delta K_{\mathrm{BL}}$ increases crack closure, and, therefore, the retardation effect should be more pronounced. On the contrary, an increase in $R$ reduces the crack closure phenomenon and, consequently weakens the transient crack growth.

\subsection{Fractography}

Fig. 9(a)-(d) show some typical features of the fatigue fracture surfaces. The crack direction is from bottom to top in all figures. The images presented were obtained close to the centre of the specimens. 

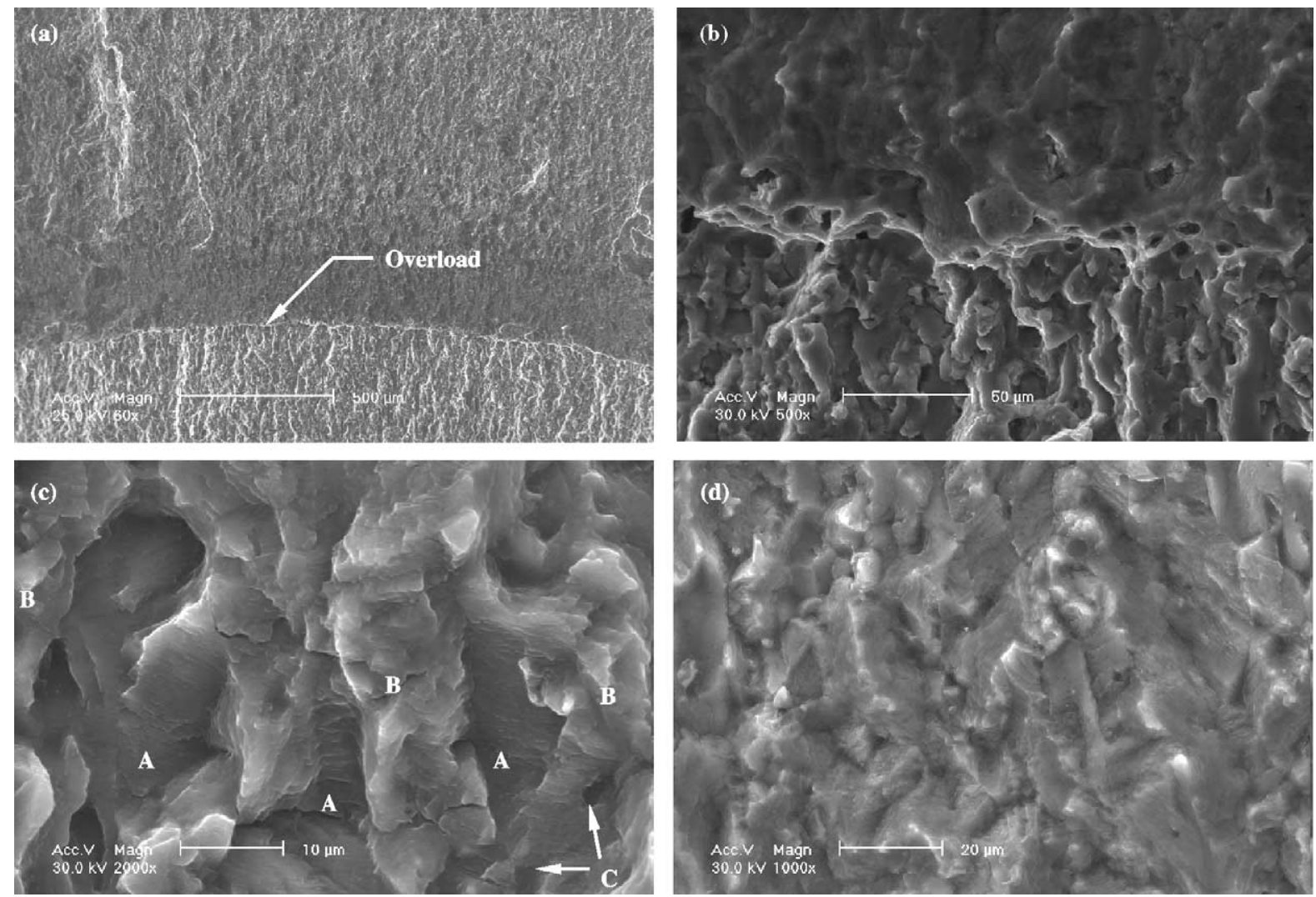

Fig. 9. SEM images of fracture surfaces $(\mathrm{OLR}=2.0$ at $R=0.05) . \Delta K_{\mathrm{BL}}=9 \mathrm{MPa} \mathrm{m}^{1 / 2}$ : (a) typical marking line and dark band observed following the overload cycle, (b) high magnification image of the overload line. High magnification images at $\Delta K_{\mathrm{BL}}=6$ $\mathrm{MPa} \mathrm{m}^{1 / 2}$ : (c) pre-overload zone, (d) post-overload fracture region.

Fig. 9(a) shows a typical marking line as well as a dark band observed following the overload cycle. Only for overloads induced at the lower $\Delta K_{\mathrm{BL}}$ level $\left(4 \mathrm{MPa} \mathrm{m}^{1 / 2}\right)$ this band was not clearly visible. Furthermore, when visible it could be followed continuously over the full thickness of the specimen. Generally the crack front corresponding to the overload cycle was slightly bowed $(<0.2 \mathrm{~mm}$ in all cases). Curved overload crack fronts were also reported for steels by Shuter and Geary [11] and Skorupa et al. [7]. These investigations also report a disappearance of the overload stretch zone near the specimen surfaces that was not seen in the present study. It was suggested [7] that these lines may have been erased due to enhanced closure in the plane stress regions near the specimen surfaces. It seems not to be the case, because for thin specimens as the ones used in our tests with a thickness of $3 \mathrm{~mm}$, the whole crack front approaches plane stress state. Fig. 9(b) is a close-up of Fig. 9(a). It can be seen that for high OLR and $\Delta K$ baseline levels crack growth during the overload cycle occurs predominantly by ductile void formation.

High magnification images, for OLR $=2$ at $\Delta K_{\mathrm{BL}}=6 \mathrm{MPa} \mathrm{m}^{1 / 2}$ and $R=0.05$, of pre-overload and postoverload fracture regions are presented in Fig. 9(c) and (d), respectively, to highlight differences between these zones. Typical fatigue fracture surfaces of this alloy have a chaotic wavy appearance and the fracture path did not seem the result from a single mechanism of fracture (see Fig. 9(c)). Fatigue fractures exhibited relatively smooth areas (labelled A) separated by tear ridges (labelled B). The smooth areas consisted predominantly of transgranular fatigue propagation containing poorly defined striations with evidence of 
secondary cracking and widely dispersed microvoid formation around second-phase particles (labelled C). The occurrence of cleaved particles in voids and the presence of unbroken particles adjacent to some voids was also observed. These observations are consistent with those reported for similar alloys [32].

Adjacent to the overload, corresponding to the dark band observed in Fig. 9(a), an intense smeared fracture zone is observed in the whole crack front (Fig. 9(d)), denoting premature contact of the crack faces. This observation provides good evidence for the enhancement of crack closure following the overload. The fracture surface smearing is more intense during the retarded growth and is gradually reduced as the crack grows outside the zone of largest plastic deformations created by the overload. Afterwards, the postoverload fracture path did not appear to differ from the pre-overload one. For high $\Delta K$ baseline levels $\left(\Delta K_{\mathrm{BL}} \geqslant 8 \mathrm{MPa} \mathrm{m}^{1 / 2}\right)$ oxide build-up at the post-overload region was also observed. The darker oxide layer was most significant at the edges of the specimen.

\subsection{Mechanisms responsible for crack growth transients}

Of the several mechanisms proposed to explain the crack growth transients following overloads [19-24], only the crack branching mechanism [23] and plasticity-induced closure [20] are able to explain the delayed retardation period that was observed for the material and loading conditions used in this work.

The crack branching mechanism can explain crack growth retardation in two ways. On one hand, crack branching or crack deflection from its original path implies a reduction of the crack driving force. On the other hand, a highly irregular crack path enhances the roughness-induced closure. In this case, the crack needs to grow some distance before the roughest fracture surfaces are behind the crack tip. Similarly, for plasticity-induced closure to affect post-overload crack growth, the crack must again growth an initial distance before the plastic zone produced by the overload starts to become a part of the plastic wake. Thus, only when the crack has propagated into the overload plastic zone can the compressive stresses cause premature contact of the crack faces.

From the crack path observation during testing no crack branching was detected at the surface of the specimens. Furthermore, significant crack deflection was only observed for OLR $=2$ at $\Delta K_{\mathrm{BL}}=9$ $\mathrm{MPa} \mathrm{m}^{1 / 2}$ and $R=0.05$. For most loading conditions it was also clearly visible that the crack was blunted by the overload and remained open at minimum load for some distance behind the crack tip. From the microroughness measurements taken across fracture surfaces no quantified difference was observed between pre-overload and post-overload regions.

Therefore, the phenomenon of plasticity-induced closure seems to be the main cause of the post-overload crack growth transients. It is suggested that the overload cycle induces crack tip blunting, which tends to remove near tip closure and reduces far field closure. Consequently, the load opening level $P_{\text {op }}$ drops below ( $U$ increases above) the value prior to the overload increasing the effective stress intensity $\Delta K_{\text {eff }}$ and, thus, leading to the brief initial crack acceleration $[4,10,15]$. The crack increment at the overload cycle also contributes to this acceleration. As the crack grows into the compressive residual stress field formed by the overload cycle it encounters increased levels of plasticity that induce near tip crack closure. This results in a gradual increase of $P_{\mathrm{op}}$, (decrease in $U$ ) which implies a gradual reduction of $\Delta K_{\text {eff }}$ and therefore of $\mathrm{d} a / \mathrm{d} N$. As the crack grows outside the zone of largest plastic deformations, $P_{\mathrm{op}}$ and, hence, $\mathrm{d} a / \mathrm{d} N$, gradually approach the values corresponding to the baseline level.

The observed effects of OLR, $\Delta K_{\mathrm{BL}}$ and $R$ on the post-overload crack growth are basically in agreement with the hypothesis that the plasticity-induced closure is the main mechanism causing retardation in 6082-T6 aluminium alloy. The higher the OLR and $\Delta K_{\mathrm{BL}}$ values the more wake plasticity is generated and, consequently, the features of the post-overload crack growth transients, namely $(\mathrm{d} a / \mathrm{d} N)_{\max }, a_{\min }$, $(\mathrm{d} a / \mathrm{d} N)_{\min }, \Delta a_{\mathrm{OL}}$ and $N_{\mathrm{D}}$, increase. On the contrary, an increase in $R$ weakens the plasticity-induced crack closure mechanism, therefore, the retardation effect should be less pronounced. 
The decrease of $a_{\mathrm{D}}$ and $N_{\mathrm{D}}$ at $\Delta K$ baseline levels above $8 \mathrm{MPa} \mathrm{m}^{1 / 2}$, seen in Figs. 6(d) and 7(a), respectively, is not necessarily in disagreement with the plasticity-induced closure argument. This effect may be due, on one hand to the higher crack-driving force associated with higher $\Delta K_{\mathrm{BL}}$ [15], on other hand to the reduction of constraint imposed by the surrounding elastic material as the overload plastic zone becomes to large [3]. In fact for these loading conditions $r_{\mathrm{OL}}$ is greater than $70 \%$ of thickness, while for $\Delta K_{\mathrm{BL}} \leqslant 8$ $\mathrm{MPa} \mathrm{m}^{1 / 2}$ is always less than $50 \%$. However, for the overload with OLR $=2$ induced at $\Delta K_{\mathrm{BL}}=9 \mathrm{MPa} \mathrm{m}{ }^{1 / 2}$ and $R=0.05$, the decrease of $a_{\mathrm{D}}$ and $N_{\mathrm{D}}$ was not observed. This fact can be explained by a crack retardation enhancement produced by the crack deflection reported earlier for this loading condition.

\subsection{Prediction from crack closure measurements}

The crack growth rates inferred directly from the closure measurements (Eq. (6)) and the characteristic $\mathrm{d} a / \mathrm{d} N$ versus $\Delta K_{\text {eff }}$ relation of the material are compared with the experimental $\mathrm{d} a / \mathrm{d} N$ in Fig. 10(a)-(d) for several loading conditions. The characteristic $\mathrm{d} a / \mathrm{d} N$ versus $\Delta K_{\text {eff }}$ relation of the material, which was determined in previous work [29], is given by Eq. (8):

$$
\begin{array}{ll}
\frac{\mathrm{d} a}{\mathrm{~d} N}=5.00 \times 10^{-8}\left(\Delta K_{\mathrm{eff}}\right)^{6.85} & \text { for } 1.1 \leqslant \Delta K_{\text {eff }} \leqslant 1.6 \\
\frac{\mathrm{d} a}{\mathrm{~d} N}=4.73 \times 10^{-7}\left(\Delta K_{\mathrm{eff}}\right)^{1.89} & \text { for } 1.6 \leqslant \Delta K_{\mathrm{eff}} \leqslant 2.5 \\
\frac{\mathrm{d} a}{\mathrm{~d} N}=1.23 \times 10^{-7}\left(\Delta K_{\mathrm{eff}}\right)^{3.39} & \text { for } 2.5 \leqslant \Delta K_{\text {eff }} \leqslant 12
\end{array}
$$

where $\mathrm{d} a / \mathrm{d} N$ and $\Delta K_{\text {eff }}$ are in $\mathrm{mm} /$ cycle and $\mathrm{MPa} \mathrm{m}^{1 / 2}$, respectively.

The inferred and measured crack growth rates show good agreement, except for the period when crack growth rates are recovering from the minimum value. Beyond this point predicted values tend to be lower than the experimental ones. Similar discrepancies have been reported for the same alloy [14], for other aluminium alloys [16] and for steels [12-15]. This behaviour is attributed to the phenomenon of discontinuous or partial closure. The fracture surfaces profile measurements of overload tests performed with OLR $=2$ at high baseline $\Delta K$ levels revealed some physical evidence in favour of this concept for 6082-T6 aluminium alloy. These measurements showed an enlarged hump of residual stretched material ahead of the overload location, as also reported in Refs. [13,15].

The appearance of the discrepancy some time after maximum retardation was also observed by Shercliff and Fleck [14] for the same alloy and for steel BS4360 50B and is consistent with the plasticity-induced crack closure argument. It is suggested that an additional increase in crack length is necessary after the minimum value of the fatigue crack growth rate is reached, so that the deformation mismatch between the plastically stretched material and the surrounding elastic material can be less severe at the crack tip than at the overload location. Afterwards the crack can be open at the tip and closed at the overload location.

It can be seen in Fig. 10 that the crack growth rates inferred using Eq. (3), for crack lengths higher than the crack increment after overloading where discontinuous closure starts, show better agreement with measured values than those inferred directly from the closure measurements. However, it is clear that there is a transition period from full closure to partial closure for crack tip increments from the overload event between $a_{1}^{*}$ and $a_{2}^{*}$, respectively, which is not taken into account by the partial closure model. Thus, a correction factor is needed in Eq. (3) to consider this transition period. For this purpose, it is suggested that Eq. (3) can be rewritten as

$$
\Delta K_{\mathrm{eff}}=K_{\max }-\frac{2}{\pi} F^{*}\left(a-a_{\mathrm{OL}}\right) K_{\mathrm{op}}
$$



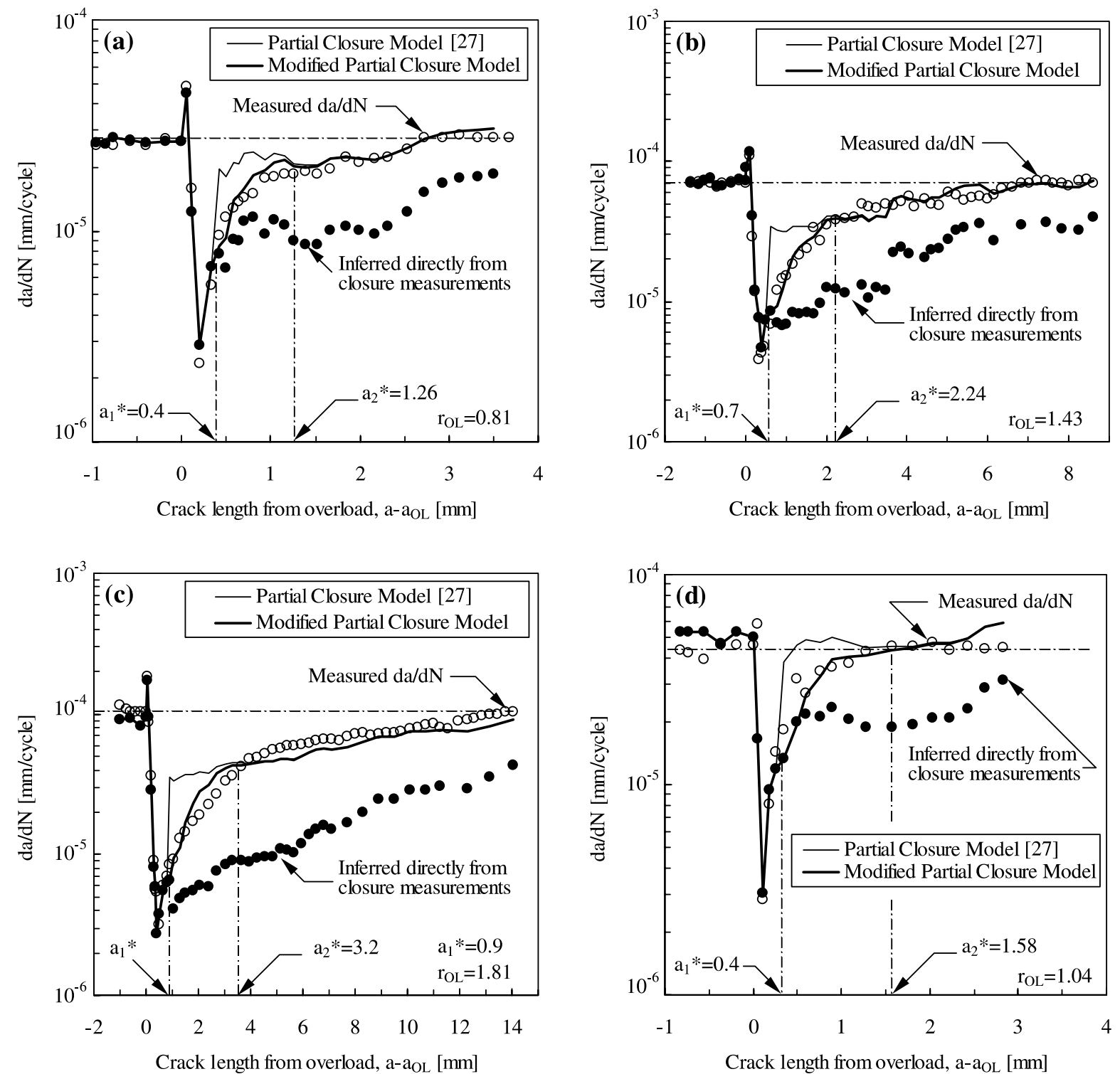

Fig. 10. Comparison of predicted from closure measurements and observed crack growth rates. OLR $=2.0, R=0.05:(\mathrm{a}) \Delta K_{\mathrm{BL}}=6$ $\mathrm{MPa} \mathrm{m}^{1 / 2}$, (b) $\Delta K_{\mathrm{BL}}=8 \mathrm{MPa} \mathrm{m}^{1 / 2}$, (c) $\Delta K_{\mathrm{BL}}=9 \mathrm{MPa} \mathrm{m}^{1 / 2}, R=0.25:$ (d) $\Delta K_{\mathrm{BL}}=6 \mathrm{MPa} \mathrm{m}^{1 / 2}$.

where $F^{*}\left(a-a_{\mathrm{OL}}\right)$ is a correction factor, function of the crack length after overloading. This function has to be equal to $\pi / 2$ for $\left(a-a_{\mathrm{OL}}\right)=a_{1}^{*}, 1$ for $\left(a-a_{\mathrm{OL}}\right) \geqslant a_{2}^{*}$ and must decay from $\pi / 2$ to 1 when $\left(a-a_{\mathrm{OL}}\right)$ increases from $a_{1}^{*}$ to $a_{2}^{*}$. Therefore, considering a parabolic decay, the following expression is proposed for $F^{*}\left(a-a_{\mathrm{OL}}\right)$

$$
F^{*}\left(a-a_{\mathrm{OL}}\right)=1+\left(\frac{\pi}{2}-1\right) \mathrm{e}^{-\pi \xi}
$$


where $\xi$ represents the fraction between the crack length after the appearance of discontinuous closure and the length of the transition period:

$$
\xi=\frac{\left(a-a_{\mathrm{OL}}\right)-a_{1}^{*}}{a_{2}^{*}-a_{1}^{*}}
$$

From analysis of crack closure data available, the point where discontinuous closure starts appears to correspond to a crack length $a_{1}^{*}$ of about $1 / 2$ of the size of the overload plastic zone evaluated from Eq. (7). Also, the transition period occurs until a crack increment after overloading of approximately $a_{2}^{*}=\pi /$ $2 \times r_{\mathrm{OL}}$ is reached. Thus, Eq. (11) can be approximated by

$$
\xi=\frac{2\left(a-a_{\mathrm{OL}}\right)-r_{\mathrm{OL}}}{r_{\mathrm{OL}}(\pi-1)}
$$

The crack growth rates inferred using Eqs. (9)-(12) for crack lengths higher than $a_{1}^{*}$ are superimposed in Fig. 10(a)-(d). It is clear that the modified partial closure model (Eqs. (9)-(11)) is able to correctly account for the partial closure phenomenon inclusively during the transition period. However, it must be emphasised that Eq. (12) was based only on the experimental data presented in this study and established for constant $\Delta K$ conditions.

It can be generalised that for overload conditions the crack opening load level indicated by a far field gauge is that at which the entire crack is open, which is not necessarily the actual crack opening load. Thus, it is worthwhile to notice that, for variable amplitude fatigue crack growth predictions based upon experimental crack closure measurements that are made remotely from the crack tip, the discontinuous closure effect must be considered.

\section{Conclusions}

From the experimental study on crack growth behaviour of 6082-T6 aluminium alloy under single tensile overload conditions, the following main conclusions can be drawn:

1. A strong influence of OLR and baseline $\Delta K$ level on the crack growth transients was observed, as expected. Basically the magnitude and extent of crack retardation increase with OLR and $\Delta K_{\mathrm{BL}}$, and decreasing $R$ ratio.

2. The length of the transient region over which crack growth rates are affected by the overload can be, depending on the loading variables, of the same order as well as much larger than the overload monotonic plastic zone calculated for plane stress conditions.

3. The $N_{\mathrm{D}} / N_{\mathrm{CA}}$ versus $\Delta K_{\mathrm{BL}}$ plots are $\mathrm{U}$ shaped curves, indicating minor and greater retardation effect, depending on OLR, for an intermediate baseline $\Delta K$ value. Thus, the OLR seems to be a major factor in determining the type of $\Delta K_{\mathrm{BL}}$ influence on the retardation effect.

4. Generally, the crack closure variation is in agreement with the effect of the different loading parameters on the crack retardation behaviour. Furthermore, the mechanism most likely to be responsible for the post-overload crack growth transients is plasticity-induced closure.

5. The crack growth rates inferred considering the phenomenon of discontinuous closure are in better agreement with measured values than those inferred directly from the closure measurements. However, the partial closure model is not able to correctly account for the observed transition period from full closure to partial closure. The proposed modification of this model improves significantly the inferred crack growth rates for all the post-overload transients. 


\section{Acknowledgement}

The authors would like to acknowledge POCTI programme, project 1999/EME/32 984, for funding the work reported.

\section{References}

[1] Vecchio RS, Hertzberg RW, Jaccard R. On the overload induced fatigue crack propagation behavior in aluminium and steel alloys. Fatigue Engng Mater Struct 1984;7(3):181-94.

[2] Ward-Close CM, Ritchie RO. On the role of crack closure mechanisms in influencing fatigue crack growth following tensile overloads in a titanium alloy: near threshold versus higher $\Delta K$ behaviour. In: Newman Jr JC, Elber W, editors. Mechanics of fatigue crack closure, ASTM STP 982. Philadelphia: American Society for Testing and Materials; 1988. p. 93-111.

[3] Venkateswara Rao KT, Ritchie RO. Micromechanisms of transient fatigue crack growth behavior in aluminium-lithium alloys following single tensile overloads. In: Petit J, Davidson DL, Suresh S, Rabbe P, editors. Fatigue crack growth under variable amplitude loading. Elsevier; 1988. p. 13446.

[4] Ward-Close CM, Blom AF, Richie RO. Mechanisms associated with transient fatigue crack growth under variable amplitude loading: an experimental and numerical study. Engng Fract Mech 1989;32(4):613-38.

[5] Krumar R, Garg SBL. Effect of yield strength and single overload cycles on effective stress intensity range ratio in 6061-T6 Alalloy. Engng Fract Mech 1989;34(2):403-12.

[6] Ling MR, Schijve J. The effect of intermediate heat treatments on overload induced retardations during fatigue crack growth in an Al-alloy. Fatigue Fract Engng Mater Struct 1992;15(5):421-30.

[7] Skorupa M, Skorupa A, Schijve J, Machniewicz T, Korbut P. Effect of specimen thickness and stress ratio on fatigue crack growth after a single overload cycle on structural steel. In: Proceedings 13th European Conference on Fracture (ICF13). Elsevier, 2000.

[8] Shin CS, Fleck NA. Overload retardation in a structural steel. Fatigue Fract Engng Mater Struct 1987;9(5):379-93.

[9] Damri D, Knott JF. Fracture modes encountered following the application of a major tensile overload cycle. Int J Fatigue 1993;15(1):53-60.

[10] Ng'Ang'a SP, James MN. Variable amplitude loading in En8 (080M40) steel: a detailed experimental study of crack growth. Fatigue Fract Engng Mater Struct 1996;19(2/3):207-16.

[11] Shuter DM, Geary W. Some aspects of fatigue crack growth retardation behaviour following tensile overloads in a structural steel. Fatigue Fract Engng Mater Struct 1996;19(2/3):185-99.

[12] Robin C, Louah M, Pluvinage G. Influence of the overload on the fatigue crack growth in steels. Fatigue Fract Engng Mater Struct 1983;6(1):1-13.

[13] Fleck NA. Influence of stress state on crack growth retardation. In: Fong JT, Fields RJ, editors. Basic questions in fatigue: vol. 1, ASTM STP 924. Philadelphia: American Society for Testing and Materials; 1988. p. 157-83.

[14] Shercliff HR, Fleck NA. Effect of specimen geometry on fatigue crack growth in plane strain-II. Overload response. Fatigue Fract Engng Mater Struct 1990;13(3):297-310.

[15] Shin CS, Hsu SH. On the mechanisms and behaviour of overload retardation in AISI 304 stainless steel. Int J Fatigue 1993;15(3):181-92.

[16] Dexter RJ, Hudak SJ, Davidson DL. Modelling and measurement of crack closure and crack growth following overloads and underloads. Engng Fracture Mech 1989;33(6):855-70.

[17] Brahma KK, Dash PK, Dattaguru B. Observations of crack closure using a crack mouth opening displacement gauge. Int J Fatigue 1989;11(1):37-41.

[18] Tsukuda H, Ogiyama H, Shiraishi T. Transient fatigue crack growth behaviour following single overloads at high stress ratios. Fatigue Fract Engng Mater Struct 1996;19(7):879-91.

[19] Shijve J, Broek D. The result of a test program based on a gust spectrum with variable amplitude loading. Aircraft Engng 1962;34:314-6.

[20] Elber W. The significance of fatigue crack closure. In: Damage tolerance in aircraft structures, ASTM STP 486. Philadelphia: American Society for Testing and Materials; 1971. p. 230-42.

[21] Christensen RH. Fatigue crack, fatigue damage and their detection. Metal fatigue. New York: MacGraw-Hill; 1959.

[22] Jones RE. Fatigue crack growth retardation after single-cycle peak overload in Ti-6Al-4V titanium alloy. Engng Fract Mech 1973;5:585-604.

[23] Suresh S. Micromechanisms of fatigue crack growth retardation following overloads. Engng Fract Mech 1983;18:577-93.

[24] Nicoletto W. Fatigue crack-tip mechanics in 7075-T6 aluminium alloy from high-sensitivity displacement field measurements. In: Nonlinear fracture mechanics: vol. I, ASTM STP 995. Philadelphia: American Society for Testing and Materials; 1989. p. 415-32.

[25] Fleck NA. Finite element analysis of plasticity-induced crack closure under plane strain conditions. Engng Fract Mech 1986;25(4):441-9. 
[26] Donald K, Paris PC. An evaluation of $\Delta K_{\text {eff }}$ estimation procedures on 6061-T6 and 2024-T3 aluminium alloys. Int J Fatigue 1999;21(Supplement):S47-57.

[27] Paris PC, Tada H, Donald JK. Service load fatigue damage — a historical perspective. Int J Fatigue 1999;21(Supplement):S35-46.

[28] Newman Jr JC. Analysis of fatigue crack growth and closure near threshold conditions for large-crack behavior. In: Newman Jr JC, Piascik RS, editors. Fatigue crack growth thresholds, endurance limits, and design, ASTM STP 1372. West Conshohocken: American Society for Testing and Materials; 1999. p. 1-25.

[29] Borrego LP, Ferreira JM, Costa JM. Fatigue crack growth and crack closure in an AlMgSi alloy. Fatigue Fract Engng Mater Struct 2001;24(4):255-65.

[30] ASTM E 647. Standard test method for measurements of fatigue crack growth rates. In: Annual book of ASTM standards: vol. 0301. Philadelphia: American Society for Testing and Materials; 1995. p. 562-98.

[31] Allison JE, Ku RC, Pompetzki MA. A comparison of measurement methods and numerical procedures for the experimental characterization of fatigue crack closure. In: Newman Jr JC, Elber W, editors. Mechanics of fatigue crack closure, ASTM STP 982. Philadelphia: American Society for Testing and Materials; 1988. p. 171-85.

[32] Bhandarkar MD, Lisagor WB. Metallurgical characterization of the fracture of aluminum alloys. In: Strauss BM, Cullen WH, editors. Fractography in failure analysis, ASTM STP 645. Philadelphia: American Society for Testing and Materials; 1978. p. 176209. 